\title{
Epithelial cell lineages in developing, restoring, and transforming liver: evidence for the existence of a 'differentiation window'
}

The liver develops as a diverticulum from an endomesodermal rudiment of the foregut, ${ }^{1}$ a restricted area of tissue that also gives rise to the ventral part of the pancreas. If these tissue differentiation options are applied at the cellular level, this means that the two organs are most probably derived from a common progenitor cell. While the exact nature of this cell is unknown, one can hypothesise that at a first approximation, it would possess several phenotypic features of stem cells. The concept of stem cells has largely been derived from findings made on adult gut and skin, two epithelial tissues undergoing continuous cell renewal. ${ }^{2}$ In both tissues, the committed progenitor (stem) cells irreversibly differentiate toward a terminal state and the specialisation process is associated with a gradual loss of the capacity of the specialising cells to proliferate. The liver, as is the case in the pancreas, exhibits a very low turnover at the adult stage. With regard to cell specialisation, the adult liver is composed of hepatocytes, biliary epithelial cells, mesothelial cells, and several types of non-epithelial cells, for example, Ito cells. ${ }^{3}$ With regard to cell growth, a remarkable feature of mature hepatocytes and mature biliary epithelial cells lies in the fact that both cell types are capable of active proliferation in the regenerating liver in response to tissue damage. ${ }^{+6}$ Thus, the need for a progenitor (stem) cell compartment is not obvious. A definitive answer to this issue is particularly important within the context of studies that aim at defining the precursor(s) of liver cancers. ${ }^{78}$

While several findings have been made on the emergence of the various cell populations in human liver, ${ }^{9}{ }^{10}$ much of our knowledge about the relations between hepatocytic and biliary epithelial cell lineages in developing liver comes from studies in the rat or mouse. ${ }^{11-13}$ In the rat, the organ emerges at embryonic day (E) 10.5 and acquires clear anatomic limits at around E12. At E10.5-12, the cells are morphologically homogenous, but differ from those at E16, when most of the phenotypic features become those of immature hepatocytes. Biliary ductal structures are clearly identifiable at around the same day. This means that the progenitor cell(s) of hepatocytes and biliary epithelial cells should constitute the main population(s) of the emerging liver. ${ }^{8}$ With this assumption in mind, we have examined the developmental features of embryonic rat liver cells by determining the differential expression of several markers at various developmental periods in situ and by evaluating in vitro the growth and differentiation potential of cells isolated at E12.814 Three types of markers have so far been considered ${ }^{8}$ Firstly, those that are related to metabolic activities. For example, E10.5 rat cells already express $\alpha$ fetoprotein whereas albumin, the most obvious marker of mature hepatocytes, appears at E11.5. ${ }^{818}$ Embryonic rat liver cells also express $\gamma$-glutamyltransferase, a typical marker of biliary ductal cells in adult liver. ${ }^{8}$ Secondly, markers that correspond to proteins that belong to the multigene family of intermediate filament proteins, particularly cytokeratins. Some 20 cytokeratins have so far been identified and their main feature as markers is that they are expressed as distinct subsets in different epithelia. ${ }^{815}$ All of the epithelial cells of the rat liver at various developmental ages express cytokeratin 8 and cytokeratin 18 , except a small population that apparently contain cytokeratin 14 instead of cytokeratin $18 .^{815}$ Biliary epithelial cells express cytokeratin 7 , cytokeratin 8 , cytokeratin 18 , and cytokeratin $19 .{ }^{815}$ Thirdly, markers of the cell surface, as shown by monoclonal antibodies directed against surface exposed components. These monoclonal antibodies have turned out to be extremely useful for the definition of the cell lineages in embryonic rat liver; for example, anti-HES 6 monoclonal antibody reacts with the surface of hepatocytes and anti-BDS $\mathrm{BD}_{7}$ monoclonal antibody decorates biliary epithelial cells beyond E15-16 in situ.

The question of whether hepatocytic and biliary epithelial cells emerge from separate or the same progenitor cells can be answered by determining the commitment of E12 cells in primary culture. ${ }^{14}$ On the basis of the sequential expression of $\alpha$ fetoprotein, albumin, cytokeratins, $\mathrm{HES}_{6}$, and $\mathrm{BDS}_{7}$, we first saw that E12 cells exposed to sodium butyrate gave rise to biliary epithelial cells whereas those exposed to serum led to typical hepatocytes. ${ }^{14}$ More recently, we found that serum could advantageously be replaced by a conditioned medium from BRL-3A cells, a population of rat liver nonparenchymal rat epithelial cells. Our conclusion is that early fetal liver cells constitute a population of bipotential progenitors capable of differentiating into hepatocytes or biliary epithelial cells ${ }^{8}$ (Fig (A)). Because E10.5-E12 cells already express the hepatocytic marker $\alpha$ fetoprotein and albumin, however, we make the hypothesis that the switch along the biliary cell lineage can also take place while differentiating progenitor cells progress through a 'differentiation window' (Figs (A), (B)), on their way to become hepatocytes. The evidence for the existence of this option comes from studies where the addition of sodium butyrate at day 5 after seeding still leads to the appearance of $\mathrm{BDS}_{7}$ positive cells at day 10 , coupled with an important reduction in albumin production (unpublished data). It is difficult at the moment to say which of the two options is used in vivo. According to this model, it should also be possible to see a switch from the biliary cell lineage in developing liver cells in vitro (Fig (B)). This possibility is currently examined in our laboratory, by submitting cultured E12 cells to sodium butyrate and BRL-3A cell conditioned medium added in various sequences.

Perhaps the most plausible evidence for a switch from biliary epithelial cells to hepatocytes comes from three lines of studies performed with cells from regenerating adult rat liver (Fig (C)). The first one concerns the use of cells isolated from 3'-methyl-4-dimethyl-aminoazobenzene (3'-Me-DAB) treated rats, a treatment that leads to a massive necrosis of the hepatic tissue followed by a rapid regeneration that includes the appearance of atypical cells, named 'oval cells'. ${ }^{16}$ These cells expressing $\mathrm{BDS}_{7}$ and $\gamma$-glutamyltransferase, the typical markers of biliary epithelial cells, were plated in fibronectin coated dishes in the presence of various growth and differen- 
tiation promoting factors and their capacity to express $\alpha$ fetoprotein, albumin, tyrosine aminotransferase and $\mathrm{HES}_{6}$ was determined. The results showed a good production of albumin plus an induction of tyrosine aminotransferase activity over a one week period, but a lack of $\mathrm{HES}_{6}$ expression. None of the culture conditions led to any significant cell growth activity. The fact that we could not induce the appearance of $\mathrm{HES}_{6}$ would suggest that the switch to the hepatocytic cell lineage does not lead to the formation of mature hepatocytes. ${ }^{16}$ The second line of work was reported by Sirica $e t a l$, who examined the liver of bile duct ligated/ $\mathrm{CCl}_{4}$ treated rats. ${ }^{17}$ The most prominent consequence of this treatment was the development of 'mixed hepatic cell cholangiolar like structures', composed of biliary epithelial cells and few hepatocytic cells that were found to be smaller than unductular adult rat hepatocytes, to express $\gamma$-glutamyltransferase and the hepatocyte specific antigen $\mathrm{H} .4$ and to be cytokeratin 19 negative. ${ }^{17}$ The third line of study concerns the cellular response to $\mathrm{D}$-galactosamine toxicity. ${ }^{12} \mathrm{~W}$ ith this protocol, hepatocytes become severely damaged and a proliferation of biliary epithelial cells precedes that of hepatocytes. ${ }^{12}$ On the basis of $\alpha$ fetoprotein, cytokeratin 7 , cytokeratin 8, cytokeratin 18, and cytokeratin 19 expression, Fausto et al also provided evidence for the presence of cells expressing both cytokeratin 19 and $\alpha$ fetoprotein. ${ }^{12}$

Therefore, on the whole, the data accumulated so far from cell lineage studies performed on cells of the developing rat liver point to the possibility that hepatocytic cells can naturally become biliary epithelial cells, whereas the findings from studies on regenerating adult rat liver support the existence of the reverse option. Our interpretation of these findings is that the switch in cell type occurs during the differentiation window (Fig (B)).

Whether mature or even immature hepatocytes in postnatal rat liver can switch to biliary epithelial cells remains an open question (Fig (C)). Our previous work on the in vitro response of cells isolated from E18 (fetal) and 2 day old (neonatal) rat livers to sodium butyrate exposure have shown a $\mathrm{BDS}_{7}$ positive biliary cell transition in less than $20 \%$ of the E18 liver derived cells and less than $5 \%$ of neonatal liver derived cells. ${ }^{16}$ No similar transition could be seen with hepatocytes isolated from adult rat liver. Our interpretation is that the $\mathrm{BDS}_{7}$ positive cells are derived from bipotential progenitors and that the number of these cells decreases rapidly during the fetal period.

As discussed above, both hepatocytes and biliary epithelial cells exhibit a low proliferative activity in primary culture. It is possible, however, to obtain preparations of non-parenchymal liver epithelial cells in primary cultures, which emerge as well defined colonies and bear no phenotypic resemblance to authentic hepatocytes and biliary epithelial cells. These liver epithelial cells can be established as cell lines and some of them can express a few of the hepatocytic metabolic activities. ${ }^{8} \mathrm{With}$ regard to the cells of origin of liver epithelial cells in vivo, it has been proposed that they are located in the terminal biliary ductules (that is, Hering canals) and could constitute a facultative hepatocytic stem cell population. ${ }^{18}$ Our recent work on their location, however, using cytokeratin 14 as a marker, has led to the conclusion that while some liver epithelial cells are localised to biliary structures, others are found in the Glisson's capsule. ${ }^{19}$ The fact that liver epithelial cells express cytokeratin 14, however, a cytokeratin typical of stratified epithelium, means that they most probably constitute a population of specialised cells. Our current view is that some liver epithelial cells represent an early sublineage of progenitor cells committed along the biliary epithelial cell lineage. ${ }^{8}$

Whether most of the cell lineage features of the normal target cell(s) of carcinogenesis are conserved in the spontaneously, chemically or virally transformed liver cells is an
A

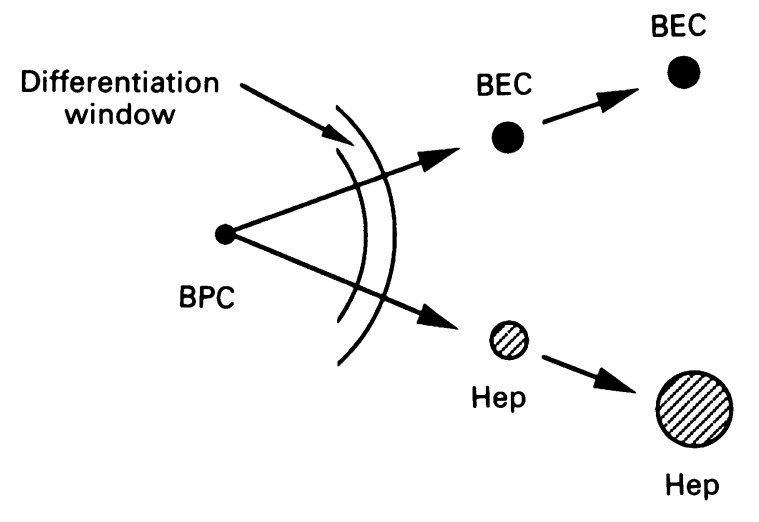

B

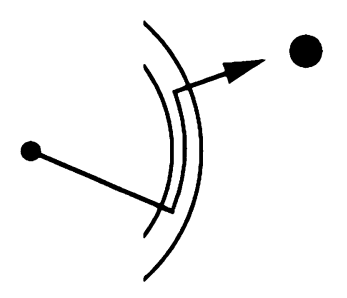

C
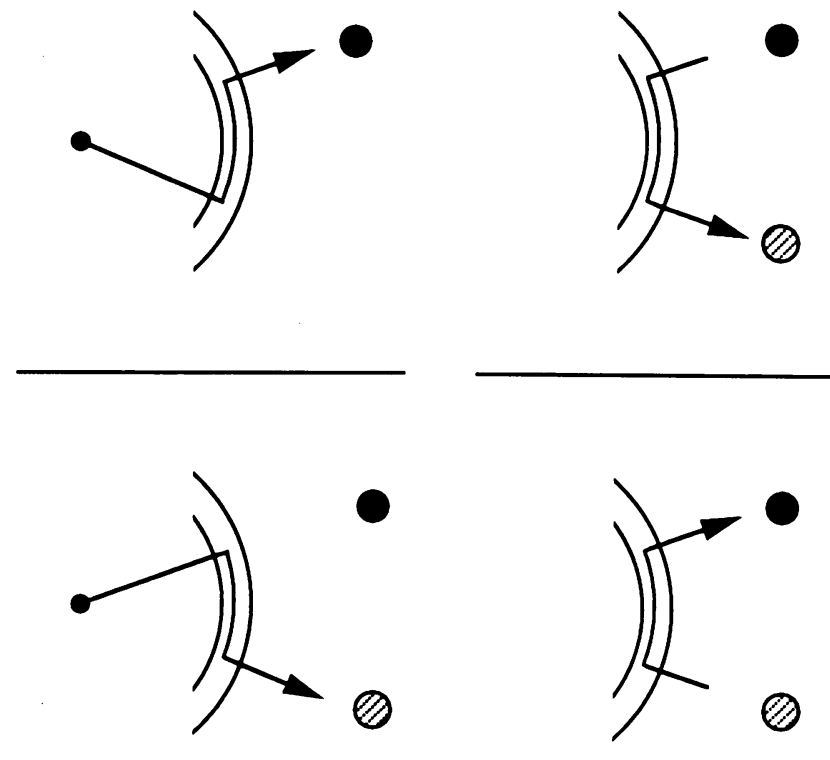

The 'differentiation window' concept. (A) Is a modified version of a previous proposal $(r e f 8) ;(B)$ and $(C)$ present the various options that can be considered in terms of cell lineage switching. $B E C=$ biliary epithelial cell, $B P C=$ bipotential progenitor cells, Hep $=$ hepatocytes.

important issue. We have recently compared the differentiated state of cells derived from the livers of carcinogen fed rats transplantable hepatocellular carcinoma and cholangiocarcinomas and concluded that both can be aligned with bipotential progenitor cells that are committed to the hepatocytic or biliary epithelial cell lineage but are blocked at intermediate steps defined by the 'differentiation window'. ${ }^{8}$ This would correspond with the stage when differentiating hepatocytes and biliary epithelial cells are most susceptible to transformation. Still, exposure of rodents to chemical hepatocarcinogens results in cellular changes that appear in a stepwise fashion. ${ }^{7}$ While important disturbances are seen in the metabolic state of a large proportion of the hepatocytes in terms of changes in the activity of enzymes participating in detoxification, it is generally believed that the tumour initiating events occur in very few target cells. ${ }^{7}$ The same type of conclusion can also be reached from studies aimed at determining the transforming activity of viral oncogenes on liver cells in culture. For example, it is possible to induce the emergence of hepatocytic (albumin positive) cells as scattered foci in cultures of adult rat hepatocytes exposed to SV40 large T DNA. ${ }^{20}$ The number of foci is low and cells from these foci are immortalised and can thus be established as cell lines. Moreover, these cell lines differ from each other morphologically and with regard to the sets of hepatocytic genes expressed..$^{20}$ When these cells obtained at high passage or containing the activated c-Ha-ras gene are transplanted in syngenic animals, they produce well differentiated hepato- 
cellular carcinomas or undifferentiated tumours. ${ }^{20} \mathrm{We}$ have recently typed some of these cell lines and found that only a few cells in the various cultures are either $\mathrm{HES}_{6}$ positive or $\mathrm{BDS}_{7}$ positive. ${ }^{8} \mathrm{We}$ proposed, again, that the cells are derived from very few progenitors in the culture that are committed to the hepatocyte lineage, but are blocked at the differentiation window.

Several studies have been reported recently on the use of transgenic mice to study immortalisation and transformation of liver cells by oncogenes under in vivo condition. ${ }^{2021}$ The rationale is based on the fact that changes in oncogenes are seen in the tumours induced by chemical hepatocarcinogens. The different transgenes (for example, SV40T, c-Ha-ras, c-myc) are directed by various liver specific gene promoters; one of them has been the mouse albumin enhancer/promoter region. ${ }^{22}$ The most rapid effects have been seen with the ras transgene. Indeed, most alb-ras transgenic founder mice died within a few days after birth, whereas the others developed focal regions of bile duct hyperplasia and dysplasia and diffuse hepatocellular dysplasia. The tumours induced by SV40T have emerged at a much lower rate but the resulting neoplasms have been typed as adenomas, hepatocellular carcinomas, cholangiomas, and cholangiocarcinomas. Although the cell of origin of these tumours is usually considered as being the hepatocytes, it has to be remembered that the albumin gene is activated in the early embryonic liver - that is, at the time when cells are bipotential progenitors for hepatocytes and biliary epithelial cells. To what extent these patterns of appearance of liver neoplasms occurring in experimental models can be used to explain the genesis of those emerging in humans, remains an important question.

In conclusion, there is no doubt that the epithelial cells of the emerging liver constitute a population of bipotential progenitors. It would seem, however, that very few of these cells remain in the organ at the adult stage. Still, severe liver damage can result in their recruitment in an attempt to boost up the tissue restoration. Cells in the early emerging liver already express a metabolic marker - that is, albumin - of the mature hepatocyte, and, therefore, one can hardly consider these early cells as stem cells (to call them hepatoblasts is inappropriate also). Instead, there is accumulating evidence pointing to the existence of a 'differentiation window' for a reverse switch in hepatocytic $v$ biliary epithelial cell lineage. With regard to transformation, it can be assumed that what happens in the liver should be similar to scenarios seen in other tissues. The fact that cell lineage features are essentially conserved in primary tumours and also that under many culture conditions one can partially reverse the differentiation block, favours the idea that the primary lesion in the origin of cancer is regulatory in nature. ${ }^{15}$ Based on data showing that characteristic lesions occur in lineage specific regions of the genome as transient events of the normal programme of cell differentiation, we propose that the transformed phenotype results from a blockage at the 'differentiation window'.

Laval University Cancer Research Center,

N MARCEAU

L'Hôtel-Dieu de Québec,

11 côte du Palais,

Québec, Québec G1R 2f6,

1 Le Douarin NM. An experimental analysis of liver development. Med Biol 1975; 53: 427.

2 Potten CS, Morris RJ. Epithelial stem cells in vivo. $\mathcal{F}$ Cell Sci 1988; 10 (suppl): 45.

3 Greengard O, Federman M, Knox WE. Cytomorphometry of developing rat liver and its application to enzymic differentiation. $\mathcal{F}$ Cell Biol 1972; 52: 261 .

4 Bucher NLR, Strain AJ. Regulatory mechanisms in hepatic regeneration. In: Millward-Sadler M, Wright $\mathrm{R}$, Arthur $\mathrm{C}$, eds. Wright's liver and biliary disease (3rd ed). Philadelphia: W B Saunders, 1992: 258-74.

5 Sirica AE, Mathis GA, Sano N, Elmore LW. Isolation, culture, and transplantation of intrahepatic biliary epithelial cells and oval cells. Pathobiology 1990; 58: 44-64.

6 Fausto N. Hepatocyte differentiation and liver progenitor cells. Curr Opin Cell Biol 1990; 2: 1036-42.

7 Farber E. On cells of origin of liver cell cancer I. In: Sirica AE, ed. The role of cell types in hepatocarcinogenesis. Boca Raton: CRC Press, 1992: 1-28.

8 Marceau N, Blouin M-J, Noël M, Török N, Loranger A. The role of bipotential progenitor cells in liver ontogenesis and neoplasia VII. In: Sirica AE, ed. The
role of cell types in hepatocarcinogenesis. Boca Raton: CRC Press, 1992: 121-50.

9 Van Eyken P, Desmet VJ. Development of intrahepatic bile ducts, ductular metaplasia of hepatocytes and cytokeratin patterns in various types of human hepatic neoplasms XI. In: Sirica AE, ed. The role of cell types in hepatocarcinohepatic neoplasms XI. In: Sirica AE, ed. The roleo
genesis. Boca Raton: CRC Press, 1992: 117-64.

10 Gerber MA, Thung SN. Cell lineages in human liver development, regeneration, and transformation $\mathrm{X}$. In: Sirica $\mathrm{AE}$, ed. The role of cell types in hepatocarcinogenesis. Boca Raton: CRC Press, 1992: 209-26.

11 Hixson DC, Faris RA, Yang L, Novikoff P. Antigenic clues to liver development, renewal and carcinogenesis: an integrated model VIII. In: Sirica AE, ed. The role of cell types in hepatocarcinogenesis. Boca Raton: CRC Press, 1992: 151-82.

12 Fausto N, Lemire JM, Shiojiri N. Oval cells in liver carcinogenesis: cell lineages in hepatic development and the identification of facultative stem cells in normal liver V. In: Sirica AE, ed. The role of cell types in hepatocarcinogenesis. Boca Raton: CRC Press, 1992: 89-108.

13 Thorgeirsson SS, Evarts RP. Growth and differentiation of stem cells in adult rat liver VI. In: Sirica AE, ed. The role of cell types in hepatocarcinogenesis. rat liver VI. In: Sirica AE, ed. The role

14 Germain L, Blouin M-J, Marceau N. Biliary epithelial and hepatocytic cell lineage relationships in embryonic rat liver as determined by the differential expression of cytokeratins, alpha-fetoprotein, albumin, and cell surfaceexpression of cytokeratins, alpha-fetoprotein, al
exposed components. Cancer Res $1988 ; 48: 4909$.

15 Marceau N. Cell lineages and differentiation programs in epidermal, urothelial and hepatic tissues and their neoplasms. Lab Invest 1990; 63: 4

16 Germain L, Noël M, Gourdeau H, Marceau N. Promotion of growth and differentiation of rat ductular oval cells in primary culture. Cancer Res 1988; 48: 368 .

17 Sirica AE, Elmore LW, Williams TW, Cole SL. Differentiation potential of hyperplastic bile ductular epithelial cells in rat models of hepatic injury and cholangiocarcinogenesis IX. In: Sirica AE, ed. The role of cell types in hepatocarcinogenesis. Boca Raton: CRC Press, 1992: 183-208.

18 Grisham JW. Cell types in rat liver cultures: their identification and isolation. Mol Cell Biochem 1983; 53/54:22.

19 Blouin R, Blouin M-J, Royal I, Grenier A, Roop DR, Loranger A, et al. Cytokeratin 14 expression in rat liver cells in culture and localization in vivo. Differentiation 1992; 52: 45-54.

20 Isom HC, Strom SC. Role of viral and cellular oncogenes and growth factors in hepatocarcinogenesis in culture and in vivo XII. In: Sirica AE, ed. The role of cell types in hepatocarcinogenesis. Boca Raton: CRC Press, 1992: 265-98.

21 Sell S, Knoll B. Transgenic mouse models of hepatocarcinogenesis XIII. In: Sirica AE, ed. The role of cell types in hepatocarcinogenesis. Boca Raton: CRC Press, 1992: 299-322.

22 Sandgren EP, Quaife CJ, Pinkert CA, Palmiter RD, Brinster RL. Oncogeneinduced liver neoplasis and transgenic Mice. Oncogene 1989; 4: 715. 